\title{
Change in Cardiovascular Risk Factors with Progression of Kidney Disease
}

\author{
Linda F. Fried ${ }^{\mathrm{a}-\mathrm{c}}$ Ronit Katz ${ }^{\mathrm{d}}$ Mary Cushman $^{\mathrm{e}}$ Mark Sarnak $^{f}$ \\ Michael G. Shlipak ${ }^{g}$ Lewis Kuller ${ }^{c}$ Anne B. Newman ${ }^{\text {b, c }}$ \\ ${ }^{a}$ Renal Section, VA Pittsburgh Healthcare System, ${ }^{b}$ Department of Medicine, University of Pittsburgh School \\ of Medicine, and 'Department of Epidemiology, Graduate School of Public Health, University of Pittsburgh, \\ Pittsburgh, Pa., ${ }^{d}$ Collaborative Health Studies, Coordinating Center, University of Washington, Seattle, Wash., \\ e Department of Medicine, Thrombosis and Hemostasis Program, University of Vermont, Burlington, Vt., \\ ${ }^{\mathrm{f}}$ Division of Nephrology, Department of Medicine, Tufts Medical Center, Boston, Mass., and ${ }^{9}$ General Internal \\ Medicine Section, San Francisco Veterans Affairs Medical Center, and Departments of Medicine, \\ Epidemiology and Biostatistics, University of California, San Francisco, Calif., USA
}

\section{Key Words}

Cardiovascular risk factors - Chronic kidney disease •

Disease progression $\cdot$ Inflammation $\cdot$ Lipids

\begin{abstract}
Background: Prior studies evaluating the relationship of kidney disease with cardiovascular risk factors have been limited by their cross-sectional design. We evaluated the change in lipids, inflammatory and procoagulant biomarkers with decline in kidney function in a nested case-cohort study in the Cardiovascular Health Study, a community-based study of adults aged $>65$ years. Methods: Individuals with an increase in serum creatinine $\geq 0.3 \mathrm{mg} / \mathrm{dl}$ (baseline to 3 years later, $n=207$ ) were matched to controls of similar age, race, gender, diabetes and baseline serum creatinine, but whose change in creatinine was $<0.3 \mathrm{mg} / \mathrm{dl}$. Baseline and change in risk factors were analyzed with conditional logistic regression. Results: Changes in C-reactive protein were similar. In contrast, cases had larger increases in fibrinogen (OR 1.38 per standard deviation, 95\% confidence interval 1.08-1.76) and factor VIII [1.38 (1.10-1.72)] and larger decreases in HDL [OR $0.80(0.64,1.00)]$. Change in interleukin- 6 was greater in
\end{abstract}

cases than controls, but this did not persist after multivariate adjustment. However, in linear regression, change in interleukin- 6 was correlated with change in creatinine. Conclusion: Cardiovascular risk factors and kidney function may change concurrently. This could lead to an increased risk of cardiovascular disease as kidney function worsens.

Copyright $\odot 2008$ S. Karger AG, Basel

\section{Introduction}

Chronic kidney disease (CKD) is associated with a high prevalence of elevated cardiovascular risk factors as well as a higher prevalence of subclinical cardiovascular disease (CVD) and clinical CVD $[1,2]$. Many studies have shown that adults with CKD have higher levels of systolic blood pressure, triglycerides, and inflammatory markers and that the levels of these markers are corre-

These data were presented in part at the Conference on Cardiovascular Disease Epidemiology and Prevention, American Heart Association, March 2006.

\section{KARGER}

(C) 2008 S. Karger AG, Basel

Fax +41613061234 E-Mail karger@karger.ch www.karger.com www.karger.com/ajn
Linda F. Fried, MD, MPH

VA Pittsburgh Healthcare System

University Drive Division, Mailstop 111F-U

Pittsburgh, PA 15240 (USA)

Tel. +1 412688 6181, Fax +1 412688 6908, E-Mail linda.fried@va.gov 
lated with the degree of kidney function $[1,2]$. This implies that as kidney disease progresses, the decline in kidney function leads to a worse risk factor profile. However, this has not clearly been shown, as most prior studies evaluating the association of CKD with cardiovascular risk factors have been cross-sectional. Nonetheless, the association of CKD with CVD is generally assumed to be mediated in part by the exacerbation of cardiovascular risk factors.

In fact, not all studies have confirmed that CKD is an independent marker of cardiovascular risk [3]. It may be that the same risk factors lead to both increased risk of CVD and to more severe kidney disease and that the kidney is not involved in causing or mediating the risk. The alternative is that CKD exacerbates cardiovascular risk factors and that the risk factors are an 'intermediate step' in the pathway from CKD to CVD. If the cardiovascular risk of CKD is attributable to the exacerbation of cardiovascular risk factors, then progression of kidney disease should be accompanied by pathophysiologic changes in risk factors such as lipids, inflammatory and thrombogenic markers.

In order to address this research question, we designed a nested case-cohort study within the Cardiovascular Health Study to examine the association of change in kidney function with change in risk factors.

\section{Methods}

\section{Participants}

The Cardiovascular Health Study [4] is a community-based cohort study of risk factors for CVD in older adults in the United States. Participants were recruited from Medicare eligibility lists in 4 communities: Forsyth County, N.C.; Pittsburgh, Pa.; Sacramento County, Calif., and Washington County, Md., USA. Individuals were invited to participate if they were community-dwelling adults, age 65 or older, expected to remain in the area for the next 3 years, were not receiving active treatment for cancer, and were able to give informed consent without a proxy. The initial cohort of 5,201 was recruited in 1989-1990 and an additional African-American cohort $(\mathrm{n}=687)$ was recruited in 1992-1993. As change was defined from initial visit to year 5 , the African-American cohort was not included in this case control study. The protocol was IRB approved and all participants gave informed consent.

As change in kidney function is relatively uncommon, a casecohort study was designed. Cases were all individuals with a rise in serum creatinine $\geq 0.3 \mathrm{mg} / \mathrm{dl}$ from the baseline visit (1989$1990)$ to the visit 3 years later (1992-1993). A change of $0.3 \mathrm{mg} / \mathrm{dl}$ was chosen as a clinically relevant change based on a review of prior studies [5]. Two hundred and seven cases were identified. These individuals were matched 1:1 with a control group having creatinine change $<0.3 \mathrm{mg} / \mathrm{dl}$. Cases and controls were matched on the individual components of the four-variable Modification of Diet in Renal Disease estimated glomerular filtration rate (GFR) formula [6]: baseline serum creatinine (within $0.2 \mathrm{mg} / \mathrm{dl}$ ), age (within 5 years), race and gender. In addition, cases and controls were matched on diabetes status [normal fasting glucose, impaired fasting glucose $110-125 \mathrm{mg} / \mathrm{dl}$ and diabetes $(\geq 126 \mathrm{mg} /$ $\mathrm{dl}$ or use of diabetic medications)]. One case with impaired fasting glucose could not be matched to a control with impaired fasting glucose and was matched to a control with diabetes.

\section{Laboratory Assays}

Serum and plasma were drawn after an 8- to 12-hour fast and samples were stored at $-70^{\circ} \mathrm{C}$. Methods regarding blood drawing, quality assurance and assay performances have been described previously [7]. Assay drift was assessed with each run of samples [7]. All assays were performed at the central lab at the University of Vermont.

Serum creatinine was measured using the Kodak Ektachem 700 Analyzer (Eastman Kodak, Rochester, N.Y., USA), a colorimetric method. The mean coefficient of variation was $1.94 \%$ (range 1.16-3.60) [7]. Cystatin C was measured using a BNII nephelometer (Dade Behring Inc., Deerfield, Ill., USA) that utilized a particle-enhanced immunonephelometric assay (N Latex Cystatin C) [8]. The interassay coefficient of variation ranges from 2.3 to $3.1 \%$.

The Olympus Demand System (Olympus, Lake Success, N.Y., USA) was used for total and HDL cholesterol and triglycerides; the mean coefficients of variation were $1.70,2.23$ and $1.84 \%$, respectively [7]. LDL cholesterol was calculated by the Friedewald formula [9]; fibrinogen was measured in a BBL fibrometer (Becton Dickinson, Cockeysville, Md., USA), mean coefficient of variation of control lots ranging from 2.53 to $3.39 \%$; factor VII and factor VIII were performed using Coag-A-Mate (Organon Teknika, Durham, N.C., USA); coefficient of variation $4.72-5.90 \%$ for factor VII and $9.10-10.37 \%$ for factor VIII [7]. Interleukin-6 (IL-6) was measured by high-sensitivity ELISA (R\&D Systems, Minneapolis, Minn., USA); the coefficient of variation was $7 \%$. Baseline C-reactive protein (CRP) was measured by high-sensitivity ELISA (coefficient of variation 5.1\%) [10]. Follow-up CRP was measured by high-sensitivity immunonephelometry on the BNII nephelometer (Dade Behring Inc.). Original values were standardized to follow-up values using linear regression (adjusted baseline CRP $=\exp [\ln ($ original baseline CRP $)+0.2781])$.

\section{Covariates}

Body weight was measured using a calibrated balance beam scale. Smoking was defined as current smoking. Use of prescription medications was ascertained from a review of prescription bottle labels by interviewers [11]. Prevalent CVD and congestive heart failure were ascertained from standardized questionnaires and were confirmed by physical exam and a review of prior records and/or treating physician surveys [12]. Prevalent CVD was defined as prior history of coronary heart disease (myocardial infarction, angina, bypass surgery, percutaneous coronary angioplasty), transient ischemic attack or stroke. The internal carotid artery was evaluated by high-resolution B-mode ultrasonography to determine the maximal intima-media thickness (IMT) as previously described [13]. Blood pressure was measured after a 5-min rest in the seated position in the right arm. An appropriately sized cuff was used. At baseline, a Hawksley random-zero sphygmoma- 
Table 1. Participant characteristics

\begin{tabular}{|c|c|c|c|}
\hline Characteristic & Cases $(n=207)$ & Controls $(\mathrm{n}=207)$ & $\mathrm{p}$ value \\
\hline Age, years & $74.1 \pm 6.1$ & $73.9 \pm 5.9$ & 0.71 \\
\hline Females & $99(47.8)$ & $99(47.8)$ & 1.00 \\
\hline Race & & & 1.00 \\
\hline White & $200(96.6)$ & $200(96.6)$ & \\
\hline Black & $6(2.9)$ & $6(2.9)$ & \\
\hline American Indian/Alaskan native & $1(0.5)$ & $1(0.5)$ & \\
\hline Diabetes status & & & 0.99 \\
\hline Normal glucose & $123(59.4)$ & $123(59.4)$ & \\
\hline Impaired fasting glucose & $30(14.5)$ & $29(14.0)$ & \\
\hline Diabetes & $54(26.1)$ & $55(26.6)$ & \\
\hline CVD & $68(33)$ & $49(24)$ & 0.04 \\
\hline Congestive heart failure & $15(7)$ & $8(4)$ & 0.13 \\
\hline Internal carotid IMT & & & $<0.001$ \\
\hline Median & 1.46 & 1.30 & \\
\hline IQR & $1.11-1.92$ & $0.94-1.65$ & \\
\hline Current Smoking & $24(11.6)$ & $19(9.2)$ & 0.57 \\
\hline Systolic blood pressure, $\mathrm{mm} \mathrm{Hg}$ & $142.6 \pm 22.9$ & $136.9 \pm 22.8$ & 0.01 \\
\hline Diastolic blood pressure, $\mathrm{mm} \mathrm{Hg}$ & $70.8 \pm 12.4$ & $70.1 \pm 11.4$ & 0.56 \\
\hline HTN medication (excluding diuretics) & $84(40.6)$ & $68(33)$ & 0.10 \\
\hline Diuretics & $82(40)$ & $60(29)$ & 0.02 \\
\hline Weight, kg & $75.7 \pm 14.5$ & $75.0 \pm 14.9$ & 0.64 \\
\hline Change in weight, lbs & $-2.9 \pm 11.6$ & $-1.5 \pm 9.7$ & 0.19 \\
\hline Waist circumference, $\mathrm{cm}$ & $97.3 \pm 12.8$ & $95.7 \pm 12.9$ & 0.20 \\
\hline Change in waist circumference, $\mathrm{cm}$ & $2.5 \pm 7.5$ & $2.8 \pm 7.4$ & 0.63 \\
\hline Estimated GFR, $\mathrm{ml} / \mathrm{min} / 1.73 \mathrm{~m}^{2}$ & $67.2 \pm 23.6$ & $66.9 \pm 22.6$ & 0.925 \\
\hline Baseline creatinine, mg/dl & $1.13 \pm 0.43$ & $1.13 \pm 0.42$ & 0.95 \\
\hline Change in creatinine, $\mathrm{mg} / \mathrm{dl}$ & $0.4 \pm 0.51(0.3$ to 6.8$)$ & $-0.03 \pm 0.10(-0.50$ to 0.20$)$ & $<0.001$ \\
\hline Baseline cystatin C, mg/dl & $1.18 \pm 0.38$ & $1.09 \pm 0.33$ & 0.03 \\
\hline Change in cystatin $\mathrm{C}, \mathrm{mg} / \mathrm{dl}$ & $0.48 \pm 0.48$ & $0.08 \pm 0.13$ & $<0.001$ \\
\hline
\end{tabular}

Figures in parentheses indicate percentages or interquartile range.

nometer (model 7076; Hawksley and Sons, Ltd., Lancing, UK) was used and at follow-up a standard mercury sphygmomanometer.

\section{Statistical Analysis}

Differences in participant characteristics between cases and controls were tested with t test or Wilcoxon test for continuous variables and $\chi^{2}$ for proportions. As the inflammatory markers are skewed, differences (baseline and change) between cases and controls in the risk factors were tested with Wilcoxon signed rank test. Conditional logistic regression (for matched pairs) was used to assess whether baseline and change in risk factors differed between cases and controls after adjustment for covariates. To determine whether the change in risk factors correlated with the degree of change in serum creatinine, the data for cases and controls were pooled and linear regression was used. S-Plus (release 6.1, Insightful, Inc., Seattle, Wash., USA) was used for the analysis. A p value $<0.05$ was considered statistically significant. Confidence intervals are expressed as 95\% confidence intervals. For the logistic and linear regression analyses, predictors are expressed per standard deviation (SD).

\section{Results}

There were 207 cases that were matched to 207 controls, who were very similar in age, gender, race, and baseline creatinine (table 1). Thus, there was a minimal difference in baseline estimated GFR. However, the cases had a significantly higher baseline cystatin $\mathrm{C}$ than controls and were also more likely to have prevalent CVD, higher IMT and systolic blood pressure and use of diuretics at baseline. By design, the change in creatinine was higher in the cases compared to the controls. The change in cystatin $\mathrm{C}$ paralleled the change in creatinine. There was no significant difference in the use of statins between the cases and controls at baseline or follow-up (3.4\% baseline, $6.8 \%$ follow-up in cases; $3.9 \%$ baseline, $4.8 \%$ followup controls). 
Table 2. Baseline and change in level of risk factors in individuals with and without worsened kidney function

\begin{tabular}{lccc}
\hline & Cases & Controls & p value \\
\hline Baseline levels & & & \\
CRP, mg/l & & \\
IL-6, pg/l & & & \\
Fibrinogen, mg/dl & $2.9(1.6$ to 7.5$)$ & $2.6(1.4$ to 4.6$)$ & 0.06 \\
Factor VII, \% & $2.2(1.3$ to 3.2$)$ & $1.8(1.2$ to 2.8$)$ & 0.01 \\
Factor VIII, $\%$ & $336 \pm 73$ & $317 \pm 66$ & 0.007 \\
HDL, mg/dl & $130 \pm 35$ & $125 \pm 28$ & 0.07 \\
LDL, mg/dl & $132 \pm 42$ & $125 \pm 39$ & 0.10 \\
Triglycerides, mg/dl & $50 \pm 15$ & $53 \pm 16$ & 0.04 \\
Change in risk factors & $127 \pm 37$ & $129 \pm 36$ & 0.51 \\
CRP, mg/l ${ }^{1}$ & $163 \pm 100$ & $143 \pm 74$ & 0.02 \\
IL-6, pg/l ${ }^{1}$ & & & \\
Fibrinogen, mg/dl & $+0.2(-0.9$ to 2.6$)$ & $+0.2(-0.8$ to 1.8$)$ & 0.65 \\
Factor VII, \% & $+1.5(0.2$ to 3.2$)$ & $+0.9(0.2$ to 1.9$)$ & 0.03 \\
Factor VIII, \% & $+23 \pm 85$ & $+10 \pm 57$ & 0.06 \\
HDL, mg/dl & $-16 \pm 29$ & $-16 \pm 19$ & 0.91 \\
LDL, mg/dl & $+60 \pm 54$ & $+44 \pm 46$ & 0.003 \\
Triglycerides, mg/dl & $-2 \pm 8$ & $-1 \pm 7$ & 0.31 \\
\hline
\end{tabular}

${ }^{1}$ Median, interquartile range.
Blood pressure tended to decrease during follow-up in the cases (median change systolic blood pressure -5 , IQ range -21.3 to $13 \mathrm{~mm} \mathrm{Hg}$ ) and diastolic $(-1.5,-10$ to 7$)$ with smaller change in controls (systolic +1 , IQ range -11 to 11 ; diastolic $+2,-4.5$ to 8 ). However, this was associated with a larger increase in the use of antihypertensives (41 vs. $33 \%$ ) and diuretics (40 vs. $29 \%$ ). Use of angiotensin-converting enzyme inhibitors (ACEIs) was uncommon in both cases and controls, though somewhat more common in cases ( 20 cases, 11 controls were taking ACEIs at baseline and 54 cases, 20 controls were taking ACEIs at year 5). Given the greater changes in antihypertensive medications, we did not analyze change in blood pressure further.

Table 2 shows the baseline values and changes in inflammatory markers, procoagulant markers and lipid values in cases and controls. Baseline inflammatory markers and factor VIIc and FVIIIc levels were higher in individuals with subsequent loss of kidney function. During follow-up, IL-6 levels increased to a greater degree in cases compared to controls. There was a borderline significant increase in fibrinogen levels, but no difference in the change in CRP during follow-up. Factor VII and VIII levels tended to be higher at baseline in cases, but only factor VIII levels changed during follow-up. Baseline HDL was higher and triglycerides were lower in cases; however, there was not a significant difference by case control status in the change in HDL, LDL or triglycerides.

Table 3 shows the results of the logistic regression analyses. The trend was towards an increase in inflammatory and procoagulant markers in cases. However, there were differences between the inflammatory and procoagulant mediators with regard to baseline values and change in cases and controls. After adjustment, baseline CRP was higher in cases than controls; however, CRP change did not differ. Fibrinogen and factor VIII increased to a greater degree in cases and HDL significantly declined. In the logistic regression, there was not a significant difference in change in IL- 6 between controls and cases. However, the change in IL- 6 did correlate with the change in creatinine, suggesting larger increases in IL-6 with larger increases in creatinine (table 4). The change in factor VIII also correlated with the change in creatinine. However, the degree of HDL and fibrinogen change did not correlate with the creatinine change.

\section{Discussion}

In this analysis, we found that several inflammatory and procoagulant marker levels increased with progression of kidney disease. The degree of change in IL-6 and 
Table 3. Odds ratios ( $95 \%$ confidence intervals) of case status (worsening kidney function) by baseline levels and changes over time of biomarkers

\begin{tabular}{|c|c|c|c|c|c|c|}
\hline Risk factors (per SD) & $\begin{array}{l}\text { Unadjusted } \\
\text { OR }(95 \% \text { CI })\end{array}$ & $\mathrm{p}$ & $\begin{array}{l}\text { Adjusted }^{1} \\
\text { OR }(95 \% \text { CI })\end{array}$ & $\mathrm{p}$ & $\begin{array}{l}\text { Adjusted }^{2} \\
\text { OR }(95 \% \text { CI })\end{array}$ & $\mathrm{p}$ \\
\hline \multicolumn{7}{|l|}{ Baseline } \\
\hline $\mathrm{CRP}, \mathrm{mg} / \mathrm{l}(11.5)$ & $1.89(1.30-2.75)$ & 0.001 & $1.73(1.20-2.51)$ & 0.004 & - & \\
\hline IL-6, pg/ml (1.6) & $1.30(1.04-1.62)$ & 0.02 & $1.16(0.93-1.44)$ & 0.19 & - & \\
\hline Fibrinogen, mg/dl (70.2) & $1.31(1.07-1.60)$ & 0.01 & $1.22(0.99-1.50)$ & 0.07 & - & \\
\hline Factor VII, \% (31.7) & $1.19(0.97-1.45)$ & 0.09 & $1.19(0.97-1.46)$ & 0.10 & - & \\
\hline Factor VIII, \% (40.9) & $1.17(0.96-1.43)$ & 0.11 & $1.11(0.91-1.37)$ & 0.30 & - & \\
\hline HDL, mg/dl (15.3) & $0.81(0.67-0.99)$ & 0.04 & $0.89(0.72-1.10)$ & 0.27 & - & \\
\hline $\mathrm{LDL}, \mathrm{mg} / \mathrm{dl}(36.4)$ & $0.93(0.76-1.13)$ & 0.46 & $0.90(0.74-1.11)$ & 0.32 & - & \\
\hline Triglycerides, mg/dl (88.6) & $1.26(1.02-1.56)$ & 0.03 & $1.17(0.94-1.45)$ & 0.17 & - & \\
\hline \multicolumn{7}{|l|}{ Change } \\
\hline CRP, mg/l (15.4) & $0.96(0.79-1.17)$ & 0.68 & $0.94(0.77-1.15)$ & 0.56 & $1.18(0.86-1.60)$ & 0.30 \\
\hline IL-6, pg/ml (2.9) & $1.28(1.04-1.59)$ & 0.02 & $1.19(0.95-1.49)$ & 0.12 & $1.22(0.98-1.53)$ & 0.08 \\
\hline Fibrinogen, mg/dl (72.7) & $1.21(0.99-1.47)$ & 0.07 & $1.17(0.95-1.43)$ & 0.14 & $1.38(1.08-1.76)$ & 0.01 \\
\hline Factor VII, \% (24.3) & $0.99(0.82-1.21)$ & 0.94 & $1.03(0.84-1.27)$ & 0.77 & $1.14(0.90-1.44)$ & 0.27 \\
\hline Factor VIII, \% (50.3) & $1.38(1.11-1.71)$ & 0.003 & $1.36(1.09-1.70)$ & 0.006 & $1.38(1.10-1.72)$ & 0.005 \\
\hline $\mathrm{HDL}, \mathrm{mg} / \mathrm{dl}(7.6)$ & $0.90(0.74-1.10)$ & 0.30 & $0.87(0.71-1.07)$ & 0.18 & $0.80(0.64-1.00)$ & 0.05 \\
\hline LDL, mg/dl (26.6) & $1.00(0.82-1.22)$ & 0.99 & $1.05(0.85-1.29)$ & 0.64 & $1.02(0.82-1.27)$ & 0.87 \\
\hline Triglycerides, mg/dl (79.7) & $1.17(0.93-1.47)$ & 0.12 & $1.19(0.92-1.53)$ & 0.09 & $1.21(0.93-1.57)$ & 0.01 \\
\hline
\end{tabular}

${ }^{1}$ Adjusted for systolic blood pressure, diuretics, prevalent CVD, internal carotid IMT.

${ }^{2}$ Adjusted for systolic blood pressure, diuretics, prevalent CVD, internal carotid IMT and baseline measure.

Table 4. Linear regression analysis combining all subjects to evaluate change in creatinine and change in risk factor

\begin{tabular}{|c|c|c|c|c|}
\hline Risk factors (per SD) & Unadjusted, OR (95\% CI) & $\mathrm{p}$ & Adjusted $^{1}$, OR (95\% CI) & $\mathrm{p}$ \\
\hline CRP, mg/l (15.4) & $-0.011(-0.055$ to 0.032$)$ & 0.61 & $-0.012(-0.055$ to 0.031$)$ & 0.57 \\
\hline IL-6, pg/ml (2.9) & $0.052(0.022$ to 0.082$)$ & 0.001 & $0.041(0.011$ to 0.071$)$ & 0.0071 \\
\hline Fibrinogen, mg/dl (72.7) & $0.027(-0.003$ to 0.057$)$ & 0.07 & $0.017(-0.012$ to 0.047$)$ & 0.24 \\
\hline Factor VII, \% (24.3) & $-0.029(-0.071$ to 0.014$)$ & 0.19 & $-0.022(-0.064$ to 0.020$)$ & 0.31 \\
\hline Factor VIII, \% (50.3) & $0.054(0.024$ to 0.083$)$ & $<0.001$ & $0.048(0.018$ to 0.077$)$ & 0.002 \\
\hline HDL, mg/dl (7.6) & $0.010(-0.034$ to 0.053$)$ & 0.66 & $0.005(-0.038$ to 0.049$)$ & 0.82 \\
\hline $\mathrm{LDL}, \mathrm{mg} / \mathrm{dl}(26.6)$ & $-0.035(-0.079$ to 0.010$)$ & 0.13 & $-0.026(-0.071$ to 0.019$)$ & 0.25 \\
\hline Triglycerides, mg/dl (79.7) & $0.025(-0.018$ to 0.068$)$ & 0.26 & $0.029(-0.013$ to 0.072$)$ & 0.17 \\
\hline
\end{tabular}

${ }^{1}$ Adjusted for age, gender, race, SBP, diuretics, prevalent CVD, internal carotid IMT.

factor VIII correlated with the degree of change in serum creatinine, indicating that greater progression of CKD may lead to greater elevations of certain inflammatory and procoagulant markers. The changes in lipid levels were not significant in univariate analysis, but after adjustment for systolic blood pressure, diuretic use, prevalent CVD, internal carotid IMT and baseline HDL, individuals with disease progression had a significant decline in HDL. We were not able to assess whether CKD led to worse blood pressure control given greater changes in $\mathrm{BP}$ medication use in individuals with progression of disease. Overall, the cardiovascular risk factor profile worsened in individuals whose kidney disease progressed compared to those whose kidney function remained stable. In addition to being potential cardiovascular risk factors, fibrinogen, factor VII and factor VII are procoagu- 
lant makers and higher levels may predict a higher risk of venous thromboembolism $[14,15]$. CKD has recently been shown to be associated with VTE, and it is possible that elevated procoagulant markers are one explanation for the increased risk [16].

The National Kidney Foundation [17] and the American Heart Association [18] consider CKD to be a coronary heart disease risk equivalent. Those who disagree about the direct contribution of CKD to risk propose that kidney disease is simply a marker of the duration and severity of traditional cardiovascular risk factor $[3,19]$. The alternative view is that CKD can exacerbate traditional risk factors or lead to the development of elevated levels of nontraditional risk factors. In NHANES I, CKD (creatinine level $1.2-1.7 \mathrm{mg} / \mathrm{dl}$ in women, $1.4-2.0 \mathrm{mg} / \mathrm{dl}$ in men) was not an independent risk factor for all-cause or cardiovascular mortality after adjustment for traditional cardiovascular risk factors [3]. In a pooled analysis of the Atherosclerosis Risk in Community Study, Cardiovascular Health Study, Framingham Heart Study and Framingham Offspring Study, CKD (eGFR $<60 \mathrm{ml} / \mathrm{min} /$ $1.73 \mathrm{~m}^{2}$ ) was associated with an increased risk of mortality [20]. The relationship was stronger in blacks compared with whites, though it was statistically significant in both. In addition, the relationship of CKD to myocardial infarction, cardiovascular mortality and stroke was only significant in blacks.

If CKD is more than a marker of other comorbidity and cardiovascular risk factors, then the progression of kidney disease should lead to exacerbation of risk factors. The rise in inflammatory and procoagulant markers is consistent with the hypothesis that CKD leads to elevations in these markers. In inflammatory kidney disease, tubular cells and mesangial cells can produce IL- 6 and tumor necrosis factor- $\alpha$ [21, 22], but as most elderly individuals with CKD do not have inflammatory kidney disease, this is not the most likely explanation. More likely explanations for the elevated levels are increased prevalence of other comorbid conditions associated with inflammation, decreased clearance of cytokines themselves or decreased clearance of other mediators that induce an inflammatory state. That the levels of inflammatory markers rise to a greater degree in individuals whose kidney function worsens suggests a role for clearance.

There were some differences among the inflammatory markers. A rise in creatinine was associated with change in IL-6, but not CRP. This could be related to decreased differences in the site of metabolism of the mediators. However, CRP does not appear to have less renal clear- ance than IL-6. In a study of the fate of recombinant human IL- 6 administered to rats, Castell et al. [23] found that $80 \%$ of IL- 6 was metabolized by the liver and $10-15 \%$ cleared by the kidney. In contrast, in a study in mice, the largest proportion of the administered CRP was recovered in the urine [24]. In human studies, approximately $90 \%$ of injected ${ }^{125}$ I-CRP is recovered in the urine [25]. An alternative explanation is that the large variability (large standard deviation) made detecting changes in CRP more difficult.

At least some of the rise of inflammatory markers with decreased kidney function is due to decreased renal clearance. However, whether a rise due to decreased renal clearance has the same clinical significance as elevated levels due to increased cytokine production is not clear. Three studies have examined whether the strength of the association of inflammatory markers with cardiovascular outcomes is the same in individuals with normal and decreased kidney function. The results are conflicting. In the Nurse's Health Study, the strength of the association of CRP, IL- 6 and tumor necrosis factor receptors for coronary artery disease events was mainly seen in individuals with decreased kidney function [26]. In the Atherosclerosis Risk in Community Study, the association of higher levels of fibrinogen with coronary heart disease was similar across all levels of renal function. In contrast, the association of lower serum albumin was stronger and the association of HDL was weaker in individuals with CKD [27]. In the Cardiovascular Health Study, CRP and factor VIII were associated with cardiovascular mortality in individuals with normal kidney function, but not those with reduced kidney function [28].

There are a number of limitations of this analysis. We did not have measured GFR and relied on changes in serum creatinine, as measured GFR is impractical for large epidemiologic studies. As individuals were matched on age, race and gender, any change in creatinine reflects a change in estimated GFR (eGFR). However, change in serum creatinine or eGFR may not accurately reflect actual change in measured GFR [29]. The two groups were matched for baseline eGFR, but the higher cystatin Clevel in the cases suggests that they may have had subtle differences in kidney function [30]. Another limitation is that kidney function and cardiovascular markers were measured at the same time points. We cannot determine which rise came first or if the markers rose concurrently. Lastly, we only had data on traditional lipid markers. CKD is associated with a decrease in LDL particle size and an increase in LDL particle number, both of which 
may be cardiovascular risk factors [31]. We did not have data on changes in nuclear magnetic resonance (NMR) lipid values to assess whether a more atherogenic lipid profile developed with worsening kidney function.

In conclusion, our results suggest that cardiovascular risk factors and kidney function may change concurrently, though there may be differences among the inflammatory markers. This could lead to an increased risk of CVD as kidney function worsens.

\section{Acknowledgements}

This material is based on work supported in part by the Office of Research and Development, Clinical Science Research and Development, Department of Veterans Affairs and was supported by contracts N01-HC-35129, N01-HC-45133, N01-HC-75150, N01HC-85079 through N01-HC-85086, N01 HC-15103, N01 HC55222, and U01 HL080295 from the National Heart, Lung, and Blood Institute, with additional contribution from the National Institute of Neurological Disorders and Stroke. Doctors Sarnak, Fried, Shlipakand Newman are supported by grant R01 AG027002. A full list of participating CHS investigators and institutions can be found at http://www.chs-nhlbi.org.

\section{References}

1 Shlipak MG, Fried LF, Crump C, Bleyer AJ, Manolio TA, Tracy RP, Furberg CD, Psaty $\mathrm{BM}$ : Cardiovascular disease risk status in elderly persons with renal insufficiency. Kidney Int 2002;62:997-1004.

2 Coresh J, Longenecker JC, Miller ER 3rd, Young HJ, Klag MJ: Epidemiology of cardiovascular risk factors in chronic renal disease. J Am Soc Nephrol 1998;9(suppl):S24-S30.

-3 Garg AX, Clark WF, Haynes RB, House AA: Moderate renal insufficiency and the risk of cardiovascular mortality: results from the NHANES I. Kidney Int 2002;61:14861494.

-4 Fried LP, Borhani NO, Enright P, Furberg CD, Gardin JM, Kronmal RA, Kuller LH, Manolio TA, Mittelmark MB, Newman A, O'Leary D, Psaty B, Rautaharju P, Tracy R: The Cardiovascular Health Study: design and rationale. Ann Epidemiol 1991;1:263276.

5 Gottlieb SS, Abraham W, Butler J, Forman DE, Loh E, Massie BM, O'Connor CM, Rich MW, Stevenson LW, Young J, Krumholz HM: The prognostic importance of different definitions of worsening renal function in congestive heart failure. J Card Fail 2002;8: 136-141.

6 National Kidney Foundation: K/DOQI clinical practice guidelines for chronic kidney disease: evaluation, classification, and stratification. Am J Kidney Dis 2002;39(suppl 1): S1-S266.

7 Cushman M, Cornell ES, Howard PR, Bovill EG, Tracy RP: Laboratory methods and quality assurance in the Cardiovascular Health Study. Clin Chem 1995;41:264-270.

-8 Erlandsen EJ, Randers E, Kristensen JH: Evaluation of the Dade Behring N Latex Cystatin $\mathrm{C}$ assay on the Dade Behring Nephelometer II System. Scand J Clin Lab Invest 1999;59:1-8

-9 Friedewald WT, Levy RI, Fredrickson DS: Estimation of the concentration of low-density lipoprotein cholesterol in plasma, without use of the preparative ultracentrifuge. Clin Chem 1972;18:499-502.
10 Macy EM, Hayes TE, Tracy RP: Variability in the measurement of $\mathrm{C}$-reactive protein in healthy subjects: implications for reference intervals and epidemiological applications. Clin Chem 1997;43:52-58.

11 Psaty BM, Lee M, Savage PJ, Rutan GH, German PS, Lyles M: Assessing the use of medications in the elderly: methods and initial experience in the Cardiovascular Health Study. The Cardiovascular Health Study Collaborative Research Group. J Clin Epidemiol 1992;45:683-692.

12 Psaty BM, Kuller LH, Bild D, Burke GL, Kittner SJ, Mittelmark M, Price TR, Rautaharju PM, Robbins J: Methods of assessing prevalent cardiovascular disease in the Cardiovascular Health Study. Ann Epidemiol 1995;5:270-277.

13 O'Leary DH, Polak JF, Wolfson SK Jr, Bond MG, Bommer W, Sheth S, Psaty BM, Sharrett AR, Manolio TA: Use of sonography to evaluate carotid atherosclerosis in the elderly. The Cardiovascular Health Study. CHS Collaborative Research Group. Stroke 1991;22: 1155-1163.

14 Feinbloom D, Bauer KA: Assessment of hemostatic risk factors in predicting arterial thrombotic events. Arterioscler Thromb Vasc Biol 2005;25:2043-2053.

15 Tsai AW, Cushman M, Rosamond WD, Heckbert SR, Tracy RP, Aleksic N, Folsom AR: Coagulation factors, inflammation markers, and venous thromboembolism: the longitudinal investigation of thromboembolism etiology (LITE). Am J Med 2002;113: 636-642.

16 Wattanakit K, Cushman M, Stehman-Breen C, Heckbert SR, Folsom AR: Chronic kidney disease increases risk for venous thromboembolism. J Am Soc Nephrol 2008;19:135140.

17 Levey AS: Controlling the epidemic of cardiovascular disease in chronic renal disease: where do we start? Am J Kidney Dis 1998, 32(suppl 3):S5-S13.
18 Sarnak MJ, Levey AS, Schoolwerth AC, Coresh J, Culleton B, Hamm LL, McCullough PA, Kasiske BL, Kelepouris E, Klag MJ, Parfrey P, Pfeffer M, Raij L, Spinosa DJ, Wilson PW: Kidney disease as a risk factor for development of cardiovascular disease: a statement from the American Heart Association Councils on Kidney in Cardiovascular Disease, High Blood Pressure Research, Clinical Cardiology, and Epidemiology and Prevention. Circulation 2003;108:2154-2169.

19 Culleton BF, Larson MG, Wilson PW, Evans JC, Parfrey PS, Levy D: Cardiovascular disease and mortality in a community-based cohort with mild renal insufficiency. Kidney Int 1999;56:2214-2219.

-20 Weiner DE, Tighiouart H, Amin MG, Stark PC, MacLeod B, Griffith JL, Salem DN, Levey AS, Sarnak MJ: Chronic kidney disease as a risk factor for cardiovascular disease and all-cause mortality: a pooled analysis of community-based studies. J Am Soc Nephrol 2004;15:1307-1315.

21 Ong AC, Fine LG: Tubular-derived cytokines and human renal disease progression. Nephrol Dial Transplant 1994;9:471-472.

22 Sterzel RB, Schulze-Lohoff E, Marx M: Cytokines and mesangial cells. Kidney Int Suppl 1993;39:S26-S31.

23 Castell JV, Geiger T, Gross V, Andus T, Walter E, Hirano T, Kishimoto T, Heinrich PC: Plasma clearance, organ distribution and target cells of interleukin-6/hepatocytestimulating factor in the rat. Eur J Biochem 1988;177:357-361.

24 Motie M, Schaul KW, Potempa LA: Biodistribution and clearance of 125I-labeled C-reactive protein and 125I-labeled modified Creactive protein in CD-1 mice. Drug Metab Dispos 1998;26:977-981.

25 Vigushin DM, Pepys MB, Hawkins PN: Metabolic and scintigraphic studies of radioiodinated human C-reactive protein in health and disease. J Clin Invest 1993;91:13511357. 
-26 Knight EL, Rimm EB, Pai JK, et al: Kidney dysfunction, inflammation, and coronary events: a prospective study. J Am Soc Nephrol 2004; 15:1897-1903.

-27 Muntner P, He J, Astor BC, Folsom AR, Coresh J: Traditional and nontraditional risk factors predict coronary heart disease in chronic kidney disease: results from the atherosclerosis risk in communities study. J Am Soc Nephrol 2005;16:529-538.
28 Shlipak MG, Fried LF, Cushman M, Manolio TA, Peterson D, Stehman-Breen C, Bleyer A, Newman A, Siscovick D, Psaty B: Cardiovascular mortality risk in chronic kidney disease: comparison of traditional and novel risk factors. JAMA 2005;293:1737-1745.

29 Levey AS, Berg RL, Gassman JJ, Hall PM, Walker WG: Creatinine filtration, secretion and excretion during progressive renal disease. Modification of Diet in Renal Disease (MDRD) Study Group. Kidney Int Suppl 1989;27:S73-S80.
30 Shlipak MG, Katz R, Sarnak MJ, Fried LF, Newman AB, Stehman-Breen C, Seliger SL, Kestenbaum B, Psaty B, Tracy RP, Siscovick DS: Cystatin $\mathrm{C}$ and prognosis for cardiovascular and kidney outcomes in elderly persons without chronic kidney disease. Ann Intern Med 2006;145:237-246.

1 Wanner C, Quaschning T: Dyslipidemia and renal disease: pathogenesis and clinical consequences. Curr Opin Nephrol Hypertens 2001;10:195-201. 